\title{
Review
}

\section{AGRICULTURE IN THE FOURTH INDUSTRIAL REVOLUTION}

\section{T. Ane ${ }^{1 *}$ and S. Yasmin ${ }^{1}$}

\begin{abstract}
Agriculture and industry are tied up and both are complementary to each other. The fourth industrial revolution is an advanced digital technology, it focuses an opportunity that could change the environment in the way human think and work. The farms and factories must implement smart technology to move very fast and it should be an innovative applications to embrace the fourth industrial revolution robustly for Bangladesh. The fourth industrial revolution concept combines artificial intelligence and big data that have achieved significant attention and popularity in precision farming like in monitoring, diagnosing insect pests, measuring soil moisture, diagnosing harvest time and monitoring crop health status and reducing complicated monitoring by human. Industry that extend precision agriculture using artificial intelligence with robotic technology in fourth industrial revolution and its application is embedding into smart observation that retrieve real-time information from field level data with minor human interference. The fourth industrial revolution builds a smart farming technology which brings advanced and sustainable changes for both production and agroprocessing. The fourth industrial revolution extends farms production and also increase their value. This paper reviewed the past effects of industrial revolution, discussed expanded benefit into smart farming and predicted impacts of fourth industrial revolution in Bangladesh agriculture.
\end{abstract}

Keywords: Smart farming, entrepreneurship, internet of things, 4IR.

\section{Introduction}

Innovative technology offers benefits such as maximize production volume and minimize the risk of failure. In industry, the first industrial revolution was started in 1780 which represented the manufacturing movement of textiles processes with the introduction of mechanical production plants used by liquid water or steam. It automated manufacturing of textiles and movement of production from homes to factories. Steam power and the cotton gin are an important objects in this period. Thirty years later, the second industrial revolution was initiated which opened the era of mass production. Late 1960s third industrial revolution was introduced. From that moment on, it was possible to automate production using electronics and information technology (IT). The fourth industrial revolution had opened in 2011 in Germany which focused computerization and an innovative production concept (Sung, 2014).

The fourth industrial revolution could not only suggest how to overcome the previous problems but also furnish the foundation for the production development adopting new forms in working applications frame for farming 4.0. Industry 4.0 brings a concept

\footnotetext{
${ }^{1}$ Department of Computer Science \& Information Technology, Bangabandhu Sheikh Mujibur Rahman Agricultural University, Gazipur 1706, Bangladesh. *Corresponding author: tanjea@bsmrau.edu.bd
} 
"collective" and "value chain" (Toanalyz, 2018). To make autonomously connection of computer based algorithm for open field agriculture, industry 4.0 builds intelligent networks among machines, work and systems in general through creating the entire value chain with the help of Internet of Things (IoT) which can control themselves and each other (Lasi et al., 2015; Xu, 2012; Hofmann, 2017; Ferracane, 2015). Industry revolution is shown in Fig 1.

The IoT leads 4IR in agricultural sector while device status can change dynamically under the environmental condition and devices can operate the next function based on the input parameter is instructed by the farmers (Zambon et al., 2019).A survey report states that, food demand is continuously growing, we will have to produce 70 percent more food grain by next 30 years (Clercq et al., 2018). Hence we should use new advanced technology to grow more food grain.

The world changes by the advanced applications of technology (Maddox, 2018). It described the applications of agriculture 4.0 which changes the business of farming. A digital farming is more productive and sustainable than the output of past. To grow more production the smart agricultural technology has no alternative. This paper illustrates the 4IR effects in short on agriculture and analyzes its impact on agricultural productivity, profitable application through large-scale farming concepts, robotic applications in agricultural farms.

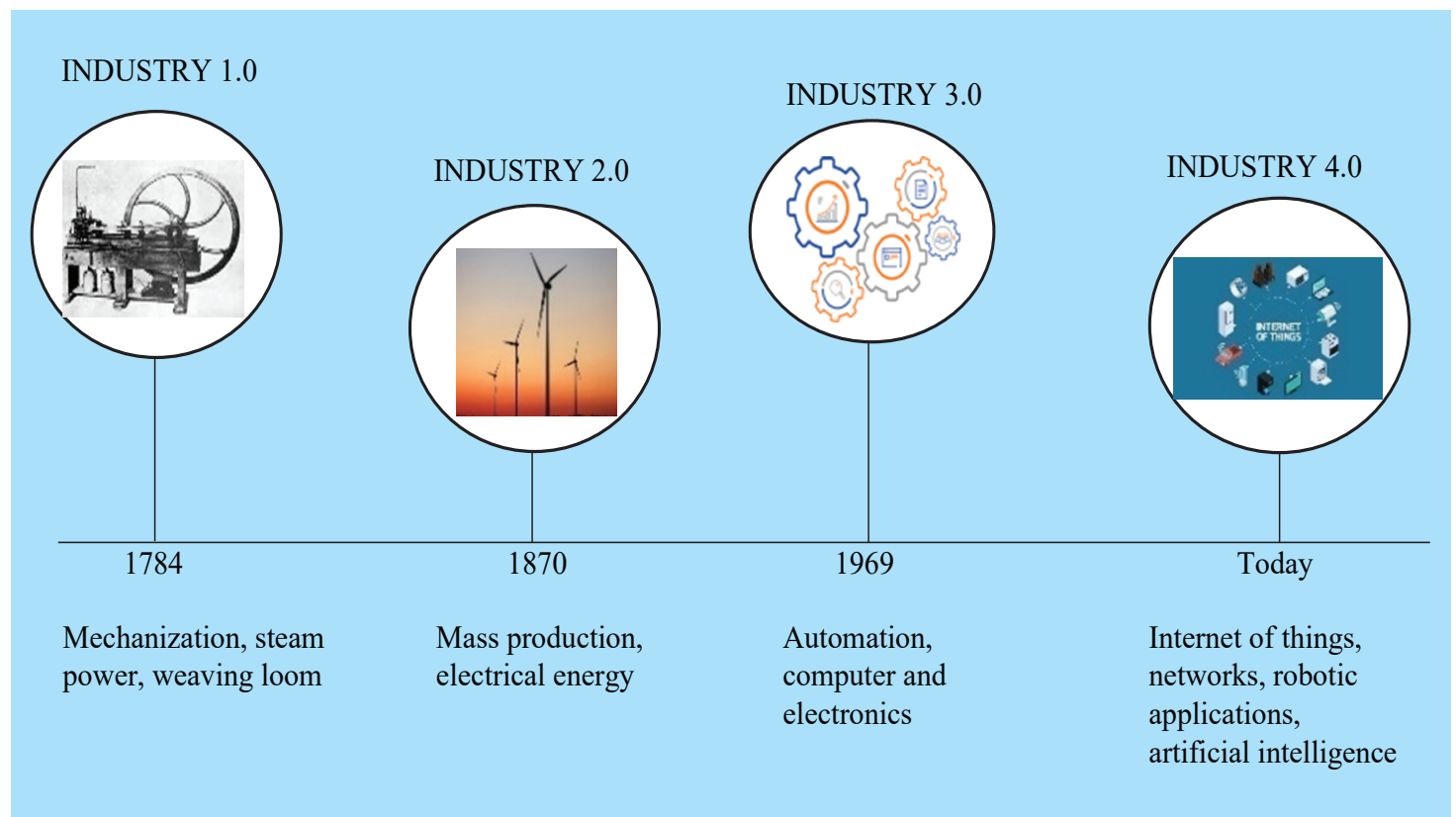

Fig. 1. From Industry 1.0 to 4.0 (Shows the industry revolution : $1^{\text {st }}$ industrial revolution used water and steam power for mechanize production, $2^{\text {nd }}$ industrial revolution for mass production using used electric power, $3^{\text {rd }}$ industrial revolution for automate production using electronics and information technology and 4IR is digital revolution that was emphasized by a fusion of technologies) [https:// www.seekmomentum.com/blog/manufacturing/the-evolution-of-industry-from-1-to-4] 


\section{Effects of 4IR on agriculture}

Traditional agricultural system cannot satisfy the growing demand of food needs without the productive support of innovative technological efficiency. Promoting 4IR effects in agriculture, first of all a convenient environment is needed to build up which is safe in rural life and environment that provides a space for cyber technology and cloud infrastructures. A smart farming culture is specified through 4IR and it allows agricultural site to enhance productivity in competitive way. 4IR applies agricultural robotics technology that has beneficial outcome for promoting advanced agricultural system reducing labor costs and increasing quality (Duckett, 2018). 4IR in agriculture suppose to include artificial intelligence, robotics technology and human workers then the smart farming outcome will be exponentially improved.

The robotis used for advanced agricultural applications such as pruning, weeding, spraying and monitoring. At the harvesting phase "harvesting robots" are used in order to expand food harvest efficiency. The development of robotic innovations is more achievable. There is a "vegetable-picking robot" which can be used for harvesting vegetables specifically. Robotic technology will operate in every area of the agricultural process such as weed control, planting seeds, harvesting, environmental monitoring and soil analysis. Therefore, robotic application has influential impact in advanced aricultural production.

Farmers will not be required to work on physically to perform any kind of actions. A robot can do with the given human commands and programs embedded on it. Interest in precision agriculture is now demanding criteria on future agricultural development which minimize environmental pollution by using harmful pesticides, fertilizers and maximize the agricultural production. Field Robots used in agriculture applications is shown in Fig 2, that demonstrates an image while tomatoes are collected by the farmers that's followed the traditional way. However, by applying robotic arms farmers can pick up fruits quick and efficient way without damaging any tomato. Programming could be set by instructions which accepts and makes rapid action based on real time information.

\section{Influence of 4IR on the rural environment}

The 4IR makes a transition period for developing countries where small farmers have to be concerned in a particularly producing food and raw materials for the urban economy. But in rural farmers most of them gets a drawbacks when come into contacting with buyers, suppliers of inputs and bankers. The 4IR has brought a vast change in manufacturing, distributing and consuming for the rural environment and life. Existing technology with technical support acts as skilled part to overcome difficult problems. Internet, web and online sites are free access in through the farmers are getting benefits in their field application, the farmers get all the update open fields information using mobile phone and the devices are connected IoT devices and cloud computing. IoT-based smart farming systems provide the rural farmers to get instant access of monitoring the light, temperature, humidity and soil moisture at fields using connected sensors with no time interval. 


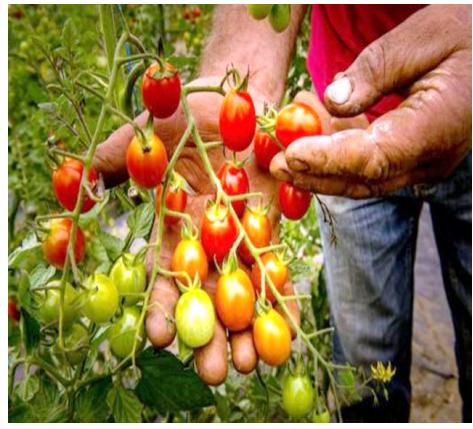

a

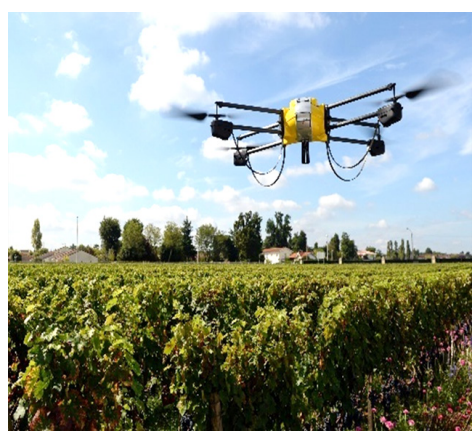

d

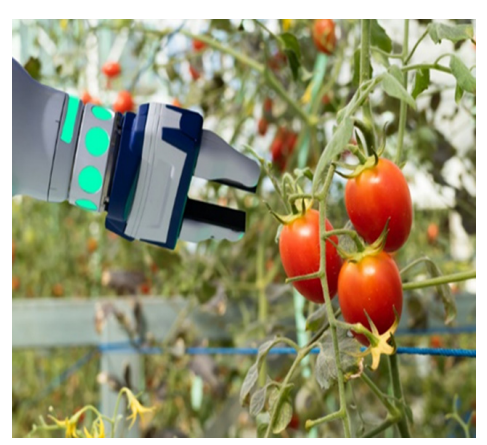

b

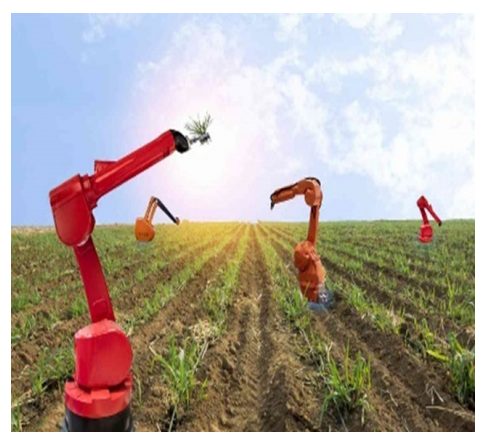

e

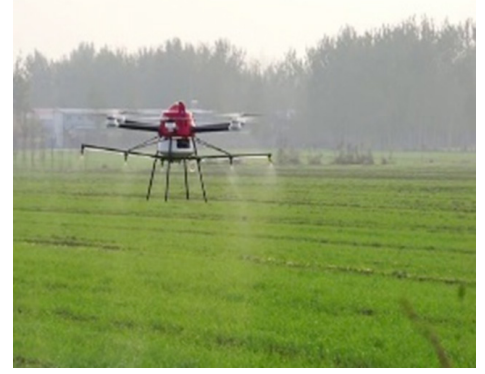

C

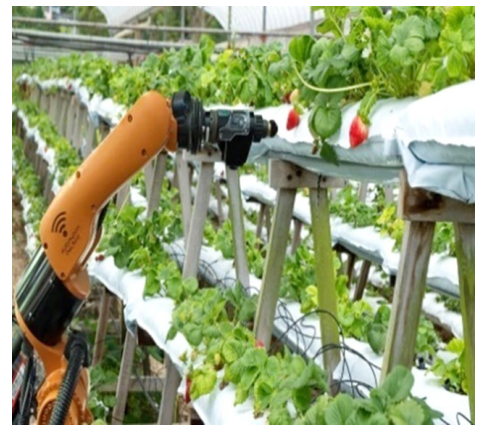

f

Fig. 2. Comparison view of traditional and modern farming sites: (a) tomato planting by man labor, (b) fields robots in agriculture, (c) spray drones, (d) agricultural drone, (e) robots harvesting plants, (f) vertical farming technology [https://www.shutterstock.com/search/agriculture+robotics]

Agricultural consumption and product distribution

Product distribution has a set of rules involved in making a product or service available for use or consumption so that it makes ensured directly and indirectly goods are available to clients. Bangladeshi farmers living in rural area may be far from direct touching from customers. In majority cases the farmers are doing farm business and there is intermediate stakeholder in between customers and farmers. That causes a gap in agricultural business. The all sectors participation is going to be helpful for better production and consumption both. 4IR can cut off the gap by creating a knowledge bridge between the farmers and make the production services available to the field workers.

It provides a clear information details in front of the clients who are directly involved in consumption and production. Real time data is demanded to choose the best one from huge production.

First to recent revolution has shown a policy while self-sufficiency is considered as first industrial revolution, second industrial revolution is for development in processing and storage technologies and third industrial revolution reviewed quantity to quality. To 
understand and manage the demand based agricultural production, crops distribution information is fetched and analyzed in computerized way by applying 4IR technology. There is a great possibility for customized production through optimizing supply and demand chain that can adjust time and output in order to keep stabilized prices normal in market (Imam et al., 2014).

\section{Increase agricultural productivity}

To increase agricultural productivity the modern technology skills can play very essential role in few ways such astransportation facilities, irrigation facilities, institutional credit, proper marketing facilities, supply of quality inputs,consolidation of holdings, agricultural education,land reforms, co-operative farming, reduction of population on land, provision of better manure seeds etc. Villagers are linked with marketing which in turns achieve the farmer's interest with better farm technology and sufficient profit.Quality of input, control field measurements and better irrigation facilities helps to increase productivity.

Marketing infrastructure and proper arrangements scope for better selling should be strengthened prices. Supplying quality inputs, controlling market prices should be check out at right time. To save the farmers from the clutches of moneylenders, adequate credit facilities, rural credit scheme and loan facility at low interest must be available to the small farmers.

To enhance crop productivity, the farmers need for agricultural education that guides the rural farmers about newly invented agricultural tools and its associated technical support. Proper crop caring may take another role for better crop production. A large part of our population is dependent on land and causes fragmentation, it creates a harmful effect for crop productivity. It immediately is needed population reduction on land. For better productivity insecticides and pesticides should be supplied properly at the low rates all over the country side. Modern technology leads to big farming which is called as cooperative farming. Now agriculture will become profitable area through large-scale farming concepts.

In this paper, we propose an approachesthat can be taken asmedium ofbetter agricultural production in Bangladesh. Many factors associated tobetter and technical way for production, 4IR can make a farmer concerned about better crop production and provides an easy access to information,product selling in actual price market and enhance the production in co-operative farming. Afterwards farmers would be connected to direct market and keep them involved inbig agribusiness.

\section{Response of 4IR in Bangladesh}

InBangladesh, since history of industrialization using 2nd or 1st IR technologies established few SME clusters. These old fashioned SME clusters performing very poor and it makes unable to cope with the modern technologies. An example can be picked up like importing coconut oil gets uncompetitive market in our country (Aninias, 2018). The local entrepreneurs get them inability to produce coconut oil as much as imported oil because they don't know the appropriate refining technology and its application so hence these poor technology used in local production farm is supposed to be exterminated. 
Industrial revolution will destroy job opprotunity in many sectors as a predition which has reported in survey but open thousand jobs in different skilled sectors. In Bangladesh top demanding technology are designing like smart phones, biometric sensors, GPS system, wifi and social media. By using applications, the human power is shifting technological based algorithm performance. Industries are growing automated. In Bangladesh development planning for sustainable economic cycle while fourth industrial revolution undoubtly is necessary. As the consequences of industrial revolution poor skilled manpower will be disappered still there, human have accessibility in choice for designing technology to make more productive system in technology oriented environment.

Digitizing agriculture farm management in collaboration with 4IR will bring a vast progressive change that expands product traceability and sustainability of smallholder farmers in Bangladesh. Knowledge development policy for new entrepreneurship is not expectedly progressing in our country. The new and potential entrepreneurs should have appropriate information about production as well as relevant mechanism to produce selected products. The number of entrepreneurs should be increased for potential entrepreneurship functional output. Government and scholars who are talking about 4IR and holding seminars, conferences, discussion forum in the media may play a vital and effective role at entrepreneurship enrollment in business that may provide knowledge for entrepreneur to apply appropriate technologies in respective fields. We should come forward to make a rapidly change in transition of 1st IR technologies into 2nd or 3rd IR technology and then it will make knowledgeable and expert system for achievement of 4IR outcomes in agriculture.

\section{Importance of robotics in agriculture}

Graphical views are presented to compare and analysis the importance of using the robotic application in agriculture. Results depicts the sales rating of robots from previous to following years and later how gradually the number of agricultural robots have been increased through the Fig. 3 and Fig. 4. From the graph (Fig. 3) illustrates worldwide industrial robot shipments increased by percent from 97,000 in 2004 to around 384,000 in 2018 (Source: Global agricultural robot revenue) and the graph (Fig. 4) shows the agricultural robot revenues between 2015 to 2024 (www.statista.com). The figures delineate the number of selling robots and the revenues from agricultural robots within years to years.

There is the period between 2004 to 2009 experienced a steady fluctuation from 97 to 60 (in 1,000 units)shipments of industrial robots in worldwide. For the period 2010-2018 it was surged from 166 to 384 (in 1,000 units). While in year 2017 to 2018 the robotic shipments was accumulated from 384 to around 382(in 1,000 units).It is obvious that sales of robot in industry has increased considerably for the following years and the revenues of the agricultural robot market worldwide is seen in following fig. 4 from years 2015 to 2024 in while the period between 2015 to 2016 experienced a steady increase the earnings from robotics in agriculture. For the period 2023-24 it was surged from 53 to 74.5. As it can be said from above two graphs, to accommodate more production oriented 


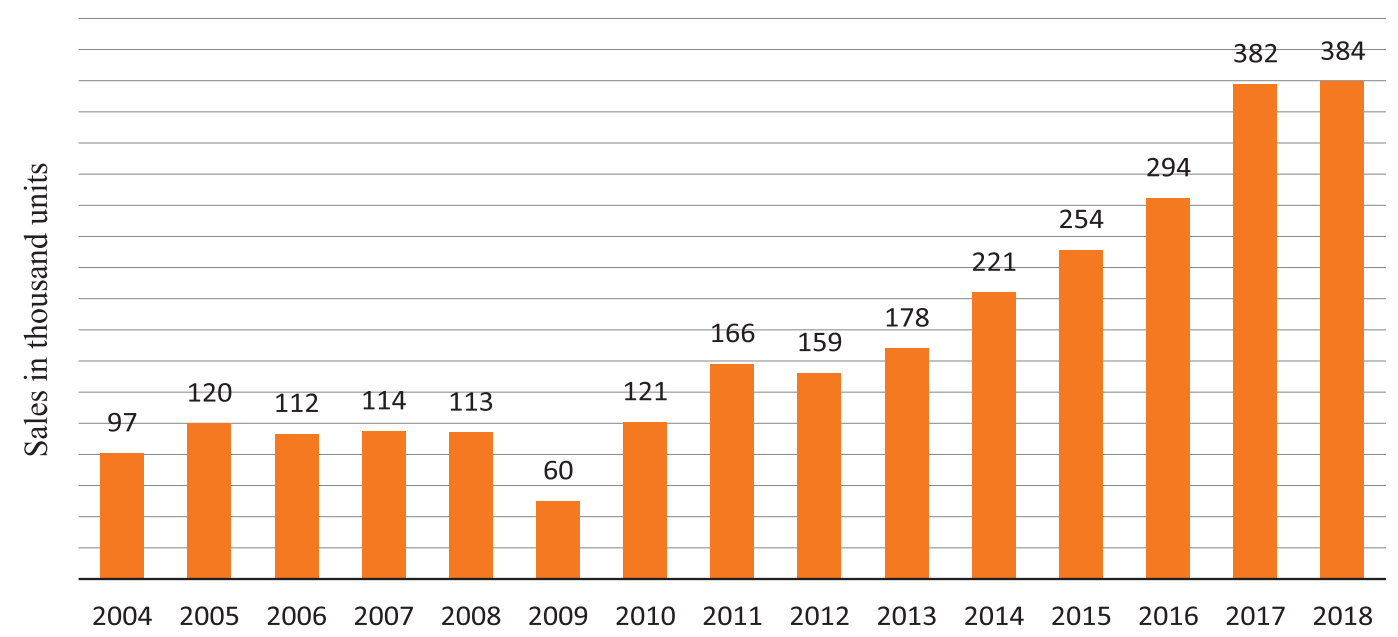

Fig. 3. Worldwide sales of industrial robots from 2004 to 2018 (in 1,000 units). Worldwide industrial robot shipments increased by one percent from about 382,000 in 2017 to around 384,000 in 2018. [Source: https://www.statista.com/statistics/264084/worldwide-sales-of-industrial-robots/ ]

a)

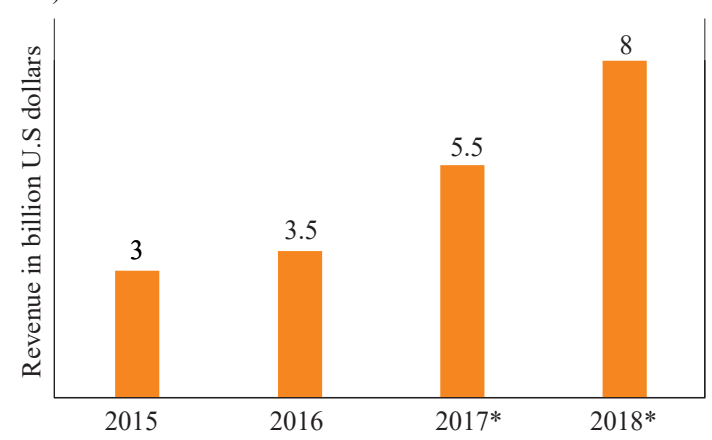

b)

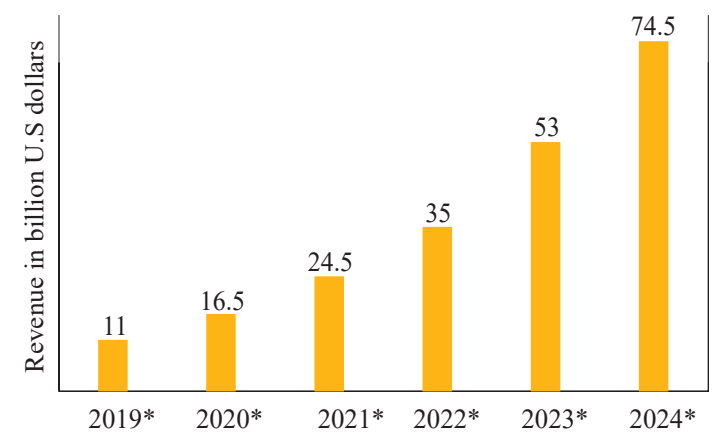

Fig. 4. Agricultural robot revenue (in billion U.S. dollars) worldwide from 2015 to 2024 in statistic result in graph (a) the agricultural robot market worldwide from 2015 to 2018, (b) the agricultural robot market worldwide from 2019 to 2024) [https:/www.statista.com/statistics/938833/agricultural-robotrevenue-worldwide/]

agricultural system there is no any little scope that we can think without accepting robotic technology for agriculture in Bangladesh.

\section{Conclusions}

Productive agriculture leads the industry to be progressive. Both agriculture and industry are interdependent. Agriculture has embraced the 4IR support to increase productivity, cut the downtime significantly and hence agriculture is becoming more technologically intelligent. It has resulted sustainable ways of farming where it allows using smart applications of internet of things and artificial intelligence for farm 
management systems. This may strengthen the farmer's ability to take field action based on real time data parameter, improve animal welfare and production quality as well as minimize harmful outputs on the environment. To achieve the goals 4IR on our agricultural ecosystem is highly required. The goal of 4IR is to provide technology-based advanced agriculture in order to meet the present demand along with updated technology. 4IR technological progress can be implemented at all sector of existing agriculture to make a huge productive changes in many intelligent ways rather than few and limited services.

\section{References:}

Aninias, R. 2018. How (and why) entrepreneurs should cash in on the coconut craze, October 11, 2018. Retrived via https:// www.bworldonline.com/sparkup-trendsworld-coconut-congress/

Clercq, De. M., A. Vats and A. Bie. 2018. Agriculture 4.0-The Future of Farming Technology, February 2018.

Duckett, T., S. Pearson, S. S. Blackmore, B. Grieve. 2018. Agricultural Robotics: The future of robotic agriculture, UK-RAS (Robotic and Autonomous System), 2018, ISSN 2398-4414

Ferracane, M. 2015. Europe. The Europian Centre for International Political Economy.

Hofmann, E. and M. Rüsch. 2017. Industry 4.0 and the current status as well as future prospects on logistics. J. Com. in Indy. 89: 23-34.

Imam, Y., B. Chibok and Y. Gamama. 2014. Channels of Distribution of Agricultural Produce in Nigeria. Journal of Biology, Agriculture and Healthcare. 4(22): 62-66
Industry 4.0 Revolution Technique, from first to fourth industrial version. Retrieved from: https://www.seekmomentum.com/blog/ manufacturing/the-evolution-of-industryfrom-1-4

Lasi, H., P. Fettke, T. Feld and M. Hoffmann. 2014. Industry 4.0. Business \& Information Systems Engineering. Journal of Service Science and Management. 6, 239-242

Maddox, T. 2018. Agriculture 4.0: How digital farming is revolutionizing the future of food. Available via: https://www.feednourishthrive. com/agriculture-4-0-digital-farmingrevolutionizing-future-food/

Agriculture robotics images. https://www.shutterstock. $\mathrm{com} / \mathrm{search} /$ agriculture+robotics

Industrial robots sales data collected from worldwide statista.com in 2004-2018. Retrieved from https:/www.statista.com/ statistics/264084/worldwide-sales-ofindustrial-robots/

Global agricultural robot revenue. https://www. statista.com/statistics/938833/agriculturalrobot-revenue-worldwide/

Sung, J. 2014. The 4IR and Precision Agriculture. DOI:10.5772/intechopen.71582.

Toanalyz, O., E. Colangelo and T. Steckel. 2018. Farming in the Era of Industry 4.0.51st CIRP Conference on Manufacturing Systems. DOI: 10.1016/j.procir.2018.03.176

$\mathrm{Xu}, \mathrm{X}$. 2012. From cloud computing to cloud manufacturing. New Zealand. https://doi. org/10.1016/j.rcim.2011.07.002

Zambon, I., M. Cecchini, G. Egidi, M. Saporito and A. Colantoni. 2019. Revolution 4.0: Industry vs. Agriculture in a Future Development for SMEs. Multidisciplinary Digital Publish Institute: processes. 7(1): 36. DOI: 10.3390/pr7010036 